\title{
STATUS FACTUAL E TEÓRICO DO PARALELOGRAMO DO DESENVOLVIMENTO DA MEMÓRIA
}

\author{
FACTUAL AND THEORETICAL STATUS OF THE MEMORY DEVELOPMENT \\ PARALLELOGRAM
}

Boris G. Meshcheryakov ${ }^{1, \star}$ (D)

RESUMO: A. N. Leontiev cunhou o termo "Paralelogramo do Desenvolvimento da Memória” (PDM) considerando a representação gráfica básica dos resultados de sua pesquisa macroontogênica sobre a memorização de palavras. Desde os anos 1990, periódicos russos sobre psicologia têm publicado muitos artigos que contestam o termo PDM, negando que represente um fato real e considerando-o uma suposta "falha" da pesquisa de Leontiev. Neste artigo, refutamos tal ideia por meio de estudos bibliográficos e empíricos, com o objetivo de estabelecer que o PDM não foi a única forma de o autor representar a memória.

Palavras-chave: Teoria cultural-histórica e da atividade. L. S. Vygotsky. A. N. Leontiev. Paralelogramo do Desenvolvimento da Memória. Memória.

ABSTRACT: A. N. Leontiev coined the term "Memory Development Parallelogram"(MDP) with regard to the basic graphic representation of the results of his macro-ontogenetic research on the memorization of words. Since the 1990s, Russian psychological journals published many articles that challenged the term MDP, denying it as a real fact, a supposed "failure" of Leontiev's research. In this article, we refute this idea by means of bibliographical as well as empirical studies, aiming to establish that MDP was not the only way the author has represented memory.

Keywords: Cultural-historical and activity theory. L. S. Vygotsky. A. N. Leontiev. Memory Development Parallelogram. Memory. 


\section{Introdução}

É bem-conhecido hoje em dia que, em meados da década de 1920, L.S. Vigotski, juntamente com A. N. Leontiev e A. R. Luria, começou a desenvolver uma visão completamente nova do funcionamento mental. A ideia central desses autores era que as funções (processos) mentais de uma pessoa, histórica e ontogeneticamente falando, não permanecem inalteradas em seu imediatismo natural; mas, de maneira semelhante ao que acontece com outras atividades, com a ajuda de ferramentas físicas, desenvolvem-se, aprimoram-se e tornam-se ações intencionais, realizadas com auxílio de ferramentas psicológicas - uma variedade de meios simbólicos. Consequentemente, o desenvolvimento mental é uma das esferas mais importantes do desenvolvimento cultural humano. Essa grande ideia abriu um amplo campo de pesquisa sobre a formação e o desenvolvimento de processos mentais mediados, pelo domínio de várias ferramentas psicológicas, como objetos, pinturas, gestos, linguagem, sistemas numéricos e outros sistemas especiais de sinais e símbolos.

Este artigo aborda especificamente o conceito introduzido por A. N. Leontiev na psicologia (LEONTIEV, 1931; LEONTIEV et al., 2003): o "Paralelogramo do Desenvolvimento da Memória" (PDM)1. Sinais claros do problema podem ser observados no fato de que, a partir da década de 1990, as principais revistas psicológicas russas publicaram diversos artigos em que o Paralelogramo de Desenvolvimento da Memória começou a ser negado como fato real (LOKHOV et al., 1993). Esse conceito é considerado até mesmo um "fracasso" na pesquisa de Leontiev, tendo sido, também, responsável pelo rompimento da parceria entre A. N. Leontiev e L. S. Vigotski (MYASOED, 2003; 2010; 2013). Além disso, também há alguma confusão quanto à compreensão do PDM como fato ou como princípio.

Pode-se, e se deve, separar pelo menos dois significados encontrados na fonte original: 1) fatos e padrões empíricos, demonstrados por A. N. Leontiev, pela primeira vez em sua pesquisa (na verdade, PDM); e 2) as ideias teóricas (declarações) usadas para interpretar esses fatos ("o princípio do paralelogramo do desenvolvimento" ou "princípio do paralelogramo") ${ }^{2}$. A. N. Leontiev apresentou claramente o conteúdo dessas ideias teóricas em seu breve prefácio "Nota do autor": "O trabalho proposto representa a experiência de um estudo monográfico baseado nos princípios fundamentais da teoria do desenvolvimento histórico de formas superiores de comportamento, proposto pela primeira vez por L. S. Vigotski e desenvolvido nos últimos anos em colaboração com A. R. Luria e conosco" (LEONTIEV et al., 2003, p. 32).

Além disso, existe um terceiro significado para o modelo hipotético ideal do PDM que, presumivelmente, pode ser derivado da teoria do desenvolvimento de funções mentais superiores (FMS) quando comparado com dados reais. Se A. N. Leontiev realmente realizou uma dedução lógica do modelo do PDM com base na teoria de L. S. Vigotski sobre o desenvolvimento de FMS e, em seguida, tomou esse modelo ideal como hipótese de sua pesquisa; então, poderíamos dizer que enriqueceu a teoria com um modelo não trivial que ele pretendia testar. A reconstrução lógica da pesquisa de A. N. Leontiev mostra que a situação era um pouco mais complicada.

Para esclarecer, é necessário salientar que existem pelo menos dois níveis de PDM (representados de várias maneiras) no trabalho de A. N. Leontiev: 1) um macrogenético - estabelecido em um estudo transversal com faixa etária variando de alunos pré-escolares a estudantes adultos -; e 2) um microgenético - estabelecido em um experimento individual formativo em crianças com retardo mental. Aqui, discutiremos os problemas associados ao PDM macrogenético. O objetivo principal é distinguir o quadro empírico e teórico real do estudo de Leontiev a partir das distorções que apareceram mais tarde na revisão crítica de seu trabalho. 


\section{Como os Fatos São Descritos?}

O termo "desenvolvimento do paralelogramo" é geralmente referido como representação visual (Fig. 1) das principais tendências no desenvolvimento de funções mentais superiores mediadas (ZAPOROZHETS; ELKONIN, 1983, p. 67).

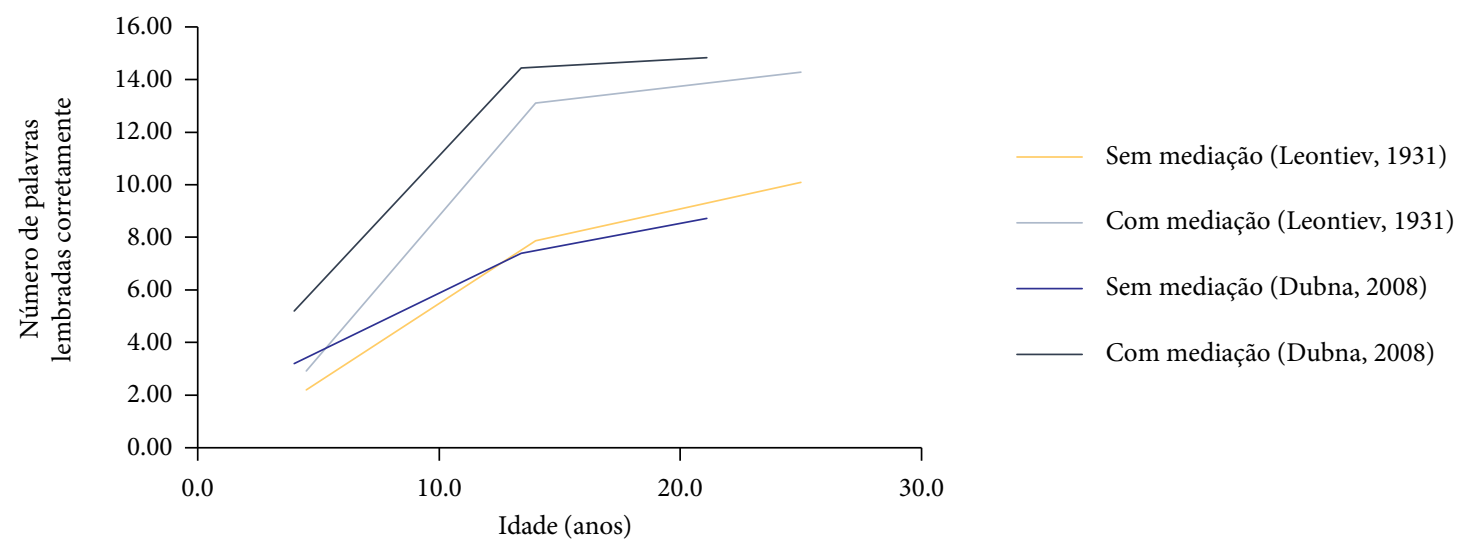

Figura 1. Representação gráfica dos dados de Leontiev (1931) e replicação dos dados (MESHCHERYAKOV et al., 2008).

A. N. Leontiev usou pelo menos três tipos de descrição: 1) uma tabela de memorização composta por estatística descritiva (média, mediana, modo, erro médio); 2) uma tabela de relações do número médio de palavras reproduzidas corretamente com e sem figuras; e 3) uma descrição verbal da regularidade empírica encontrada:

O padrão geral que emerge aqui pode ser formulado desta maneira: a partir da idade pré-escolar, a taxa de desenvolvimento da memorização com a ajuda de meios externos é muito maior do que a taxa de desenvolvimento da memorização sem a ajuda de cartões; e vice-versa, a partir da primeira idade escolar, o aumento nos indicadores de memorização externa direta é mais rápido que um aumento adicional na memorização mediada (LEONTIEV et al., 2003, p. 83).

É claro que o centro semântico dessa descrição é a afirmação sobre a heterocronia das taxas de crescimento dos índices de memorização em duas condições experimentais: na idade pré-escolar, o indicador de memorização mediada externamente aumenta mais rapidamente, V1 (em comparação com o indicador de memorização direta externa, V0, como visto na nota 4). O oposto acontece no Ensino Fundamental (Tabela 1).

O mesmo padrão pode ser descrito de maneira diferente: a relação dos indicadores V1 e V0 em função da idade (bem como em função do desenvolvimento cultural) tem a forma de uma função invertida em forma de U; ou seja, cresce na idade pré-escolar, mas, em algum momento do início da idade escolar, começa a diminuir. Ao analisar os dados, A. N. Leontiev usou o "coeficiente de aumento relativo": $\mathrm{k}=(\mathrm{V} 1$ - V0)/V0 (cujo valor é apenas 1 a menos que o valor da relação dos indicadores V1 e V0). A. N. Leontiev fornece os seguintes coeficientes de aumento relativo (k) (LEONTIEV et al., 2003, p. 81). 
Tabela 1. Coeficientes de aumento relativo (k) para diferentes grupos etários (LEONTIEV, 2003).

\begin{tabular}{ccccccc}
\hline \multirow{2}{*}{$\begin{array}{c}\text { Grupo- } \\
\text { controle }\end{array}$} & \multicolumn{2}{c}{ Pré-escolares } & \multicolumn{2}{c}{ Ensino Fundamental I } & Ensino Fundamental II & Estudantes \\
\cline { 2 - 7 } & $\begin{array}{c}\mathbf{4} \text { a } 5 \\
\text { anos }\end{array}$ & $\begin{array}{c}\text { 6 a } 7 \\
\text { anos }\end{array}$ & $\begin{array}{c}\text { Grupos I-II } \\
(\mathbf{7} \text { a 12 anos })\end{array}$ & $\begin{array}{c}\text { Grupos III-IV } \\
(\mathbf{1 0} \text { a 14 anos })\end{array}$ & $\begin{array}{c}\text { Grupos V-VI } \\
(\mathbf{1 2} \text { a 16 anos })\end{array}$ & 22 a 28 anos \\
\hline $\mathrm{k}$ & 0,38 & 0,72 & 0,82 & 0,71 & 0,66 & 0,42 \\
\hline
\end{tabular}

É óbvio que os coeficientes de aumento relativo apresentados na tabela confirmam o padrão geral formulado. Em relação ao grau de generalidade desse padrão, deve-se notar que pode estar limitado aos meios de mediação externa. Experimentos em que as imagens foram substituídas por letras sugeriram que o PDM se move na escala etária para a direita. Além disso, em pré-escolares de 4 a 5 e de 6 a 7 anos, os indicadores de memorização mediada externamente são significativamente menores do que sem mediação externa (MESHCHERYAKOV et al., 2008). A substituição de figuras por letras (mnemônicos para a primeira letra) permitiu a Leontiev identificar um longo período inicial, em que esse método não apenas não ajudou, mas também dificultou a memorização (Fig. 2). Também é notável que, para a mediação com letras, o padrão geral estabelecido por A. N. Leontiev, quanto à taxa de desenvolvimento, acabou sendo, em geral, correto.

A comparação dessas diferentes maneiras de descrever dados leva à conclusão de que eles não são equivalentes. Assim, a questão é: "Qual das quatro formas de apresentação dos resultados é considerada pertinente e quais são dispensáveis?” A forma gráfica mais discutida é o "paralelogramo”. A. N. Leontiev mostrou convincentemente que essa forma de representação pode variar bastante sob a influência de vários fatores experimentais. O autor definiu o padrão ("subjacente"):

[A] forma gráfica de expressão dessa relação pode ser mais ou menos flexível, mas a lei subjacente permanece inalterada. Podemos encontrá-la em nossos testes experimentais e nas atuais pesquisas, bem como na pesquisa sobre a memorização por adultos pertencentes a diferentes níveis culturais, e na pesquisa sobre o desenvolvimento da atenção mediada em crianças e, finalmente, com uma longa pesquisa sobre o desenvolvimento da memorização em indivíduos (LEONTIEV et al., 2003, p. 84).

É interessante analisar alguns exemplos de como os dados de A. N Leontiev foram obtidos e como outros pesquisadores os descreveram.

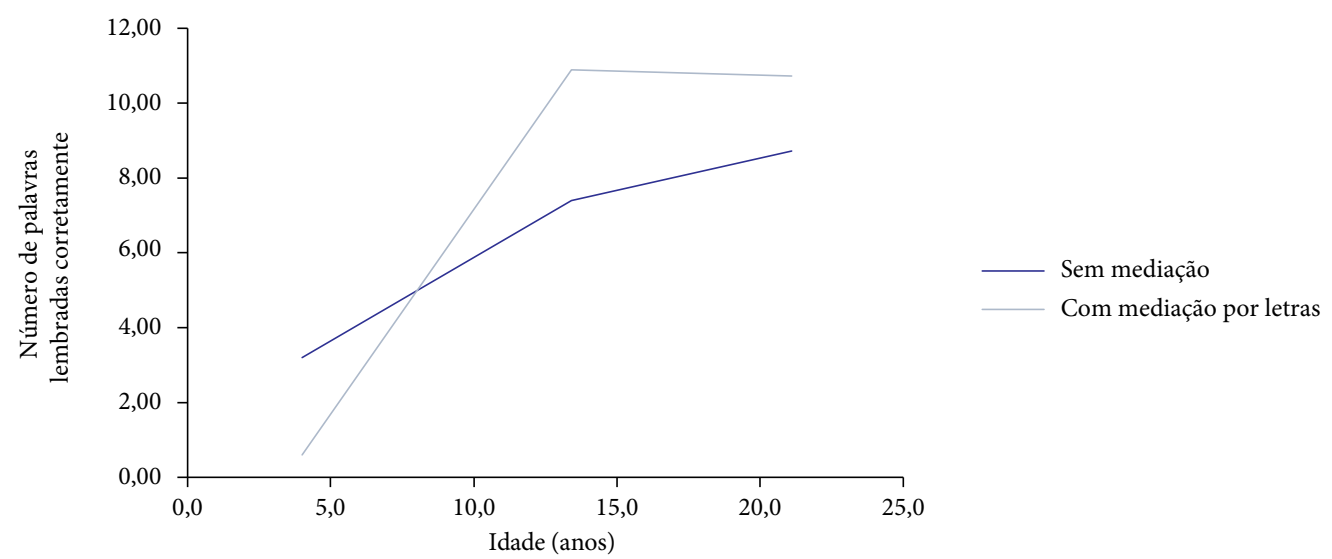

Figura 2. A substituição de figuras por letras (lembrança da primeira letra) permitiu identificar um período inicial em que a mediação cria dificuldades 
Comecemos com um exemplo que não usa o nome "paralelogramo". P. P. Blonsky, em seu livro Pedologia, para estudantes de pedagogia ([1934]2006, p. 300), adota duas formas de apresentação de dados também usadas por A. N. Leontiev: representação gráfica e uma tabela de indicadores de memorização (e suas razões). Blonsky apresenta brevemente a pesquisa de A. N. Leontiev: o "paralelogramo do desenvolvimento", a ideia de "internalização" e até a memorização mediada internamente não são mencionados, e a curva mais baixa no gráfico de Leontiev é chamada "curva de desenvolvimento da memória natural" (termo nem um pouco adequado à memória voluntária verbal). P. P. Blonsky caracteriza "memória mediada” como o uso de auxílios externos à memorização: livros, cadernos, tabelas, notas etc. O principal resultado da pesquisa de A. N. Leontiev sobre a memória é descrito da seguinte maneira: “[...] na idade pré-escolar mais avançada, a chamada memória mediada se desenvolve rapidamente, a um ritmo mais rápido (quase 1,5 vez mais rápido) do que a memória natural" (BLONSKY, 2006, p. 299).

Uma das descrições mais completas da pesquisa inteira de A. N. Leontiev é apresentada por A. V. Zaporozhets e D. B. Elkonin (1979). Tais autores não se limitaram a descrever apenas pesquisas macrogenéticas (em sua terminologia, genéticas comparativas), mas atribuíram, também, grande valor à continuação dessa pesquisa no "experimento formativo", observando que era "o primeiro e único estudo de tipo genético experimental nessa fase do desenvolvimento da teoria" ( ZAPOROZHETS; ELKONIN, 1979, p. 15).

O PDM é considerado uma das descobertas de A. N. Leontiev:

A primeira descoberta pode ser descrita da seguinte maneira. O assim chamado "paralelogramo do desenvolvimento" foi obtido comparando-se a relação entre os processos de memorização direta e de memorização mediada em diferentes idades (pré-escolar, escolar e em adultos). Sua essência está em dois fatos: o primeiro foi que, nos pontos inicial e final, ou seja, nas crianças mais novas e nos adultos, não há diferenças significativas entre os resultados da memorização direta e mediada por meios externos (figuras). O segundo resultado mostrou que, no meio desses polos (ou seja, na idade escolar), existem grandes diferenças entre essas duas formas de memorização. A memorização indireta é muito mais produtiva que a mediada. As curvas de desenvolvimento das duas formas de memorização progridem de tal maneira que, na primeira metade, a memorização direta não revela mudanças visíveis, enquanto as formas mediadas produzem mudanças significativas e, inversamente, na segunda metade, as formas mediadas não mudam significativamente, mas a memorização direta sim. Esses resultados deveriam ter sido explicados de alguma forma. Em sua base, surgiu a sugestão de que, por trás do aumento da produtividade da memorização direta, na segunda metade da curva, esteja a transformação de formas diretas em formas mediadas, quando a memorização direta desaparece, transformando-se em memorização oculta, mediada internamente e usando meios internos, não externos (ZAPOROZHETS; ELKONIN, 1979, p. 15).

Dois pontos controversos devem ser observados nessa descrição. Primeiramente, a excessiva idealização da forma gráfica do PDM (consultar o primeiro resultado mencionado). Leontiev não concordaria com esse argumento (como exposto adiante).

Em segundo lugar, a afirmação de que a ideia de transformar formas diretas em mediadas tenha se originado como hipótese após A. N. Leontiev descobrir que o PDM (ou seja, apenas na interpretação dos resultados) também é controverso. Em nossa opinião, a ideia da "transformação de formas diretas em mediadas" foi incluída nos fundamentos teóricos sobre os quais A. N. Leontiev se debruçou antes de iniciar a pesquisa, além de estar contida na hipótese da pesquisa. No entanto, A. N. Leontiev não derivou o modelo 
do paralelogramo correto a partir dessa hipótese, nem no estágio preliminar, nem no post factum. Até onde sabemos, ninguém o fez até agora.

A descrição do PDM por L. S. Vigotski é de grande interesse. Infelizmente, o texto mais apropriado (História do desenvolvimento de funções mentais superiores. Capítulo 10: "Desenvolvimento de funções mnemônicas e mnemotécnicas”, em VIGOTSKI, 1983, p. 239-254) contém contradições e imprecisões estranhas, deixadas sem comentários pelo editor do volume na coletânea em questão. No entanto, Vigotski descreveu os resultados de A. N. Leontiev, tentando não idealizar a forma do PDM: "A curva inferior, referente aos processos de memorização direta, começa rápida e acentuadamente a subir para a curva superior e sobe ainda mais, enquanto a taxa de subida da curva superior, pelo contrário, diminui a velocidade e se estabiliza um pouco" (VIGOTSKI, 1983, p. 247).

L. S. Vigotski, portanto, não afirma que "não há diferenças significativas" nos pontos finais do "paralelogramo". Ele reconhece apenas o fato de "ter sido elaborado", "uma tendência das curvas a convergir" etc.

A. N. Leontiev chama atenção para o fato de que a forma do PDM é um pouco parecida com o paralelogramo perfeito, como segue: "Assim, as linhas de desenvolvimento, em sua representação gráfica convencional, são duas curvas que se aproximam nos limites inferior e superior e compõem uma forma que se assemelha à figura de um paralelogramo não completamente regular, com dois cantos cortados" ( LEONTIEV et al., 2003, p. 83, grifos nossos); "A seguir, denotaremos brevemente esse padrão de desenvolvimento da memorização pelo termo condicional 'paralelogramo do desenvolvimento"' (LEONTIEV et al., p. 87-88).

Essas características significam que o termo estabelecido por A. N. Leontiev pode ser chamado "paralelogramo" apenas metaforicamente - ou seja, figurativamente (ver também MESHCHERYAKOV et al., 2008; MESHCHERYAKOV, 2013) - e deveria ter sido chamado, apropriadamente, paralelogramo de Leontiev. A base para a escolha do nome "paralelogramo" foi, talvez, uma analogia distante, mas muito inspiradora, ao conhecido princípio (ou regra) da mecânica: o paralelogramo de forças. No entanto, olhando para os gráficos de A. N. Leontiev, seria possível inventar outro nome, bem mais preciso que "paralelogramo", pois esse conceito inclui um retângulo e um quadrado, que não correspondem à regularidade empírica detectada. Além disso, se apresentarmos graficamente os coeficientes do aumento relativo (k) em função da idade (estágios de desenvolvimento cultural), obteremos uma função invertida em forma de U, que poderia ser chamada de "parábola de Leontiev". (De fato, ele também usou essas representações gráficas em seu livro.)

Está claro que A. N. Leontiev considerou esses gráficos de importância teórica fundamental, do ponto de vista das previsões da teoria do desenvolvimento das FMS. Portanto, tomemos o PDM não apenas como resultado empírico, mas também como princípio explicativo.

Em um artigo do ano de 2003, P. A. Myasoed intitulou um parágrafo inteiro "Existe um paralelogramo!" Tal parágrafo termina com uma declaração: “A. N. Leontiev tinha razão em falar sobre o 'paralelogramo do desenvolvimento da memória” (MYASOED, 2003, p. 111). No entanto, nos próximos dois artigos escritos pelo autor, as conclusões são contraditórias. Myasoed diz: "Confiando nos dados, A. N. Leontiev tinha o direito de falar sobre o paralelogramo do desenvolvimento da memória" (MYASOED, 2010, p. 118), e na página seguinte: “O paralelogramo que A. N. Leontiev procurou não existe "( MYASOED, 2010, p. 119). Após três anos, o mesmo autor escreve: "Esse 'paralelogramo' é baseado nas opiniões de L. S. Vigotski [...] não existe no trabalho original. Contudo, o fato permanece e, dando crédito ao pesquisador que o descobriu, podemos falar do paralelogramo de Leontiev" (MYASOED, 2013, p. 113).

Se P. A. Myasoed implicava que A. N. Leontiev procurava o paralelogramo perfeito, então reiterar a conclusão sobre sua inexistência não representa nenhuma novidade; isso estava muito claro para L. S. Vigotski e A. N. Leontiev. No entanto, essa afirmação trivial é usada para produzir outra conclusão: "A afirmação de A. N. Leontiev de que a ontogênese da memorização obedece ao 'princípio do paralelogramo' não é confirmada" 
(MYASOED, 2003, p. 106; ver também p. 116). Então, conclui-se algo sério: L. S. Vigotski e A. N. Leontiev seguiram caminhos diferentes porque discordaram sobre a prova do princípio do paralelogramo e da ideia de 'internalização"' (MYASOED, 2003, p. 114).

Seguindo esse caminho, consideramos, genuinamente, que há motivo para críticas à metodologia empírica de Leontiev, bem como à análise de dados. Vamos considerar alguns destes problemas.

1. Não há imagens dos sinais auxiliares utilizados no teste com mediação.

2. Existem faixas etárias amplas e sobrepostas, que não permitem uma comparação simples de faixas etárias discretas.

Por exemplo, crianças de 12 anos de idade, no experimento de Leontiev, foram simultaneamente divididas em três grupos "sociais": escolares I-II (7 a 12 anos); III-IV (10 a 14 anos); e V-VI (12 a 16 anos). Além disso, não está claro como o autor distribuiu os participantes nas faixas etárias.

Leontiev considerava o "nível educacional" (não a idade) uma variável básica. No entanto, isso não justifica sua decisão, o que Myasoed também corrobora, de considerar o eixo horizontal (x) uniforme (i.e., de que os dados de cada faixa etária sejam colocados a distâncias iguais entre si). Segundo nossa perspectiva, seria extremamente desejável replicar o experimento de Leontiev com faixas etárias mais estreitas para usar a idade média como variável independente.

3. Leontiev não imprimiu o texto das instruções para todas as séries escolares e faixas etárias (há apenas uma instrução para a recordação mediada; ver LEONTIEV et al., 2003, p. 78). É óbvio que as instruções para crianças em idade pré-escolar e em primeiro grau devem ter sido diferentes das instruções para os alunos da última série escolar e pós-escolarização.

4. Para demonstrar o paralelogramo do desenvolvimento, Leontiev usou amplo conjunto de faixas etárias: pré-escolares, escolares e pós-escolares.

Obviamente, para construir o paralelogramo do desenvolvimento, foi necessário reduzir as faixas etárias para três. O principal problema é que as bases do reagrupamento de Leontiev não são claras. Por que todos os alunos devem ficar juntos? Poderia ter sido aceitável se a primeira série diferisse essencialmente da última e, por sua vez, a última série diferisse dos alunos pós-escolarização. No entanto, Leontiev não projetou o experimento dessa maneira.

Um dos objetivos de nossa pesquisa (MESHCHERYAKOV et al., 2008) foi replicar a pesquisa clássica realizada por A. N. Leontiev (Fig. 1) nas crianças atuais. Além de duas condições experimentais introduzidas por A. N. Leontiev (i. e., memorização sem mediação e memorização mediada por figuras), nossa pesquisa incluiu outra: a memorização mediada por letras, que tornou possível "deslocar" o paralelogramo (metafórico) para a direita, ao longo da escala etária. Construímos o paralelogramo nos três pontos seguintes: pré-escolares mais novos, escolares da $8^{a}$ série e estudantes universitários. Construímos os mesmos diagramas dos dados de A. N. Leontiev para três faixas etárias fechadas: crianças pré-escolares mais jovens (4 a 5 anos), adolescentes (12 a 16 anos) e estudantes após a escolarização.

As seguintes conclusões podem ser tiradas dos resultados obtidos no estudo:

1. A dinâmica da idade para reproduzir palavras na memorização não mediada e mediada por figuras é semelhante à descrita por A. N. Leontiev (Fig. 1);

2. O método experimental de Leontiev provou-se confiável e resistente a variações processuais; 
3. A memória mediada se desenvolve mais rapidamente nas crianças pré-escolares atuais do que nas crianças da década de 1920;

4. A aplicação de um método de memorização mais difícil, mediado por letras, em crianças préescolares resulta na redução de sua capacidade de reproduzir palavras em comparação com a memorização direta (Fig. 2);

5. Estudos têm mostrado que crianças nos anos finais da pré-escola e nos iniciais do Ensino Fundamental usam, na maioria dos casos, a regra mnemônica da primeira letra corretamente. No entanto, isso não as ajuda a lembrar palavras com mais eficácia. Como a memorização mediada no estágio de aquisição de meios é menos eficaz que a memorização direta, um modelo mais apropriado seria um paralelogramo com duas "caudas", que representariam o estágio de interiorização das operações usando meios mnemônicos.

\section{"O Princípio do Paralelogramo"}

A. N. Leontiev, baseando-se precisamente na teoria histórico-cultural, propôs uma interpretação qualitativa das curvas ontogenéticas da produtividade da memória para duas condições (memorização com ou sem a ajuda de figuras) ${ }^{3}$ e, ao mesmo tempo, não afirmou que a teoria de Vigotski fosse acurada em predizer o correto paralelogramo para as condições experimentais construídas.

Passaremos ao texto de Leontiev para colocar algumas questões e responder a elas: "O 'princípio do paralelogramo' foi proposto como hipótese de pesquisa?"; "Foi derivado da teoria de Vigotski?"; "O autor forneceu alguma justificativa para a aceitabilidade de sua pesquisa na verificação da hipótese do PDM?”; "Como A. N. Leontiev formulou uma hipótese de pesquisa?"

Seguindo Vigotski e Luria, Leontiev et al. (2003, p. 70) dizem que, primeiramente, a hipótese tem uma forma muito geral e não operacionalizada; não há nenhum indício do PDM em sua formulação. Em segundo lugar, não se afirma nada original em comparação com as principais ideias de L. S. Vigotski sobre o desenvolvimento das FMS. Certamente, essa hipótese deve ser chamada "hipótese de Vigotski”, como confirmam Leontiev e Sokolova. Tais autores acrescentam que "o desenvolvimento de formas superiores de processos mentais passa pelo uso de signos-estímulo” (LEONTIEV et al., 2003, p. 8). Embora adotada por A. N. Leontiev, a hipótese não forneceu previsão quantitativa precisa dos resultados, mas, obviamente, era esperado que, na condição sem figuras (memorização externa não mediada, como o autor escreve com precisão), os alunos mais velhos e, especialmente, os adultos demonstrassem aumento significativo na eficiência da memorização em comparação com pré-escolares e escolares mais jovens. Esse crescimento deve-se ao desenvolvimento da memorização mediada internamente, que, por sua vez, deve-se ao domínio prévio de meios e métodos externos de memorização.

A. N. Leontiev não previu que o fragmento do lado direito da linha inferior, o qual refletia o aumento da eficiência da memorização externamente não mediada, seria estritamente paralelo à linha de crescimento da eficiência da memorização mediada externamente (com figuras) em pré-escolares e escolares mais jovens; tampouco previu que os indicadores de memorização nas duas condições seriam iguais no caso de adultos. Na formulação da hipótese de A. N. Leontiev, o fato de que os indicadores de memorização "sobem" na condição sem figuras em direção aos indicadores de memorização na condição com figuras é muito importante e difícil de negar. Portanto, existem certos motivos para dizer que os resultados são consistentes com a hipótese.

Assim, notamos que uma hipótese bastante geral foi apresentada originalmente, o que é consistente com a dinâmica do aumento relativo dos coeficientes (k) identificados e da forma do PDM metafórico. 
Esse resultado empírico foi elevado ao status de "lei empírica”, versão confirmada por L. S. Vigotski: "Esse fenômeno foi observado pela primeira vez durante o processamento de material experimental por A. N. Leontiev, o qual também foi o primeiro a formular a lei" (VIGOTSKI, 1983, p. 247).

Por fim, o que significa o "princípio do desenvolvimento do paralelogramo"? A. N. Leontiev diz ser expressão da lei que o desenvolvimento das FMS “ocorra por meio do desenvolvimento da memorização com a ajuda de sinais de estímulo externos” (LEONTIEV et al., 2003, p. 88, grifos nossos).

Claramente, essa formulação significa que o "princípio do paralelogramo" é apenas outro nome para a mesma e original "hipótese de Vigotski", mas formulada de maneira mais sucinta que antes (como citado anteriormente).

Como já apresentado, A. N. Leontiev e seus colegas acreditavam que os dados empíricos que emergiram em um estudo macrogenético fossem coerentes com a "hipótese de Vigotski" (i. e., com os resultados que A. N. Leontiev chamou "princípio do paralelogramo"). No entanto, há outro ponto de vista, expresso e persistentemente defendido por P. A. Myasoed (2003; 2010; 2013): "Formulado por A. N. Leontiev, o 'princípio do paralelogramo' não é devidamente confirmado: as curvas experimentais obedecem a diferentes leis matemáticas, não se cruzam nem indicam duas linhas separadas de ontogênese” (MYASOED, 2013, p. 116). Mais especificamente, P. A. Myasoed declara duas objeções: 1) diferenças nas funções que aproximam as curvas de desenvolvimento superior e inferior que formam o paralelogramo metafórico de Leontiev; e 2) a diferença entre a eficiência da memorização para as duas condições (com e sem figuras) em indivíduos adultos (estudantes). Para nós, não parece que esses argumentos sejam suficientes para confundir A. N. Leontiev e desacreditar completamente do "princípio do paralelogramo".

Em primeiro lugar, diferentes formas de funções são facilmente explicadas do ponto de vista da teoria de L. S Vigotski pelo fato de que a curva superior não inicia na mesma fase de desenvolvimento que a curva inferior, mas começa em uma fase posterior; ou seja, a seção inicial é cortada na curva superior, o que a curva inferior demonstra claramente (de acordo com A. N. Leontiev, essa seção reflete uma memorização puramente direta). Em segundo lugar, a diferença de eficiência é simplesmente explicada pela distinção na complexidade das próprias tarefas. Leontiev sabia muito bem que a tarefa de memorizar com figuras era muito mais fácil do que memorizar sem elas (LEONTIEV et al., 2003).

No entanto, é importante entender que o "princípio do paralelogramo" não explica nem prevê as formas exatas das funções dos índices de memorização para as duas condições experimentais; de qualquer forma, não exige que sejam iguais nem implica um paralelismo dessas funções. Por isso, exercícios de aproximação são cruciais. O "princípio do paralelogramo" explica a heterocronia do crescimento dos indicadores de memória em duas condições, conforme declarado nos padrões de desenvolvimento de memória anteriormente mencionados. Claramente, criticamos a insuficiência do "princípio do paralelogramo", mas, na ausência de uma explicação melhor, não há razão para rejeitá-lo.

Sem dúvida, a ideia de "internalização" é abordada no "princípio do paralelogramo" (mais precisamente, na "hipótese de Vigotski”); ou seja, na posição teórica da teoria das FMS. No entanto, em sua pesquisa macrogenética, A. N. Leontiev não abordou a tarefa de testar a hipótese de "internalização".

Deve-se estar ciente de que A. N. Leontiev sempre usou a palavra "internalização" entre aspas, obviamente, apontando para o sentido metafórico do termo. É fácil verificar, a partir da análise do texto O Desenvolvimento da Memória, que seu autor sabia que, em um estudo macrogenético (transversal), era absurdo procurar o processo de "internalização". A análise das idéias metodológicas de A. N. Leontiev sobre o estudo de "internalização" e sua implementação no estudo microgenético desse autor usando o método genético experimental merecem um artigo em separado. 


\section{Agradecimento}

As organizadoras do dossiê agradecem a Lucia Reily pela revisão técnica do texto em inglês e agradecem à Juana Marques Pereira Curi pela tradução do mesmo para o português.

\section{Notas}

1. A edição de 2003 (LEONTIEV et al., 2003) será usada para citações em virtude de suas maiores acessibilidade e máxima proximidade da edição original da A. N. Leontiev (1931).

2. A palavra "memória” não faz parte do termo, uma vez que o princípio é comum a diferentes funções.

3. O nome "memorização direta" (outro termo era "memória natural", como no caso de P. P. Blonsky) é amplamente usado para a condição sem figuras, o que é extremamente lamentável, graças ao fato de que, segundo a interpretação de A. N. Leontiev, nessa condição, apenas a memorização de pré-escolares e estudantes mais jovens pode ser imediata. Por isso, surge a dissonância conceitual, quando a curva inferior de seus gráficos é chamada curva de memorização direta. Em vez disso, deveria ser chamada "cronograma de desenvolvimento da memorização mediada internamente" (A. N. Leontiev preferia o nome "memorização externa direta"). Além disso, curva superior deveria ser chamada "cronograma de desenvolvimento da memorização mediada externamente" (na qual, de acordo com A. N. Leontiev, também existem meios e métodos internos).

\section{REFERÊNCIAS}

BLONSKY, P. P. (1934). Pedologiya [Pedology] and Psikhologiya mladshego shkol'nika [Psychology of the younger schoolchild]. Izbrannyye psikhologicheskiye trudy. Moscow: Izd-vo Mosk. Psikhologosotsial'nogo Instituta/Voronezh: Izd-vo NPO «Modek», 2006. p. 24-459.

LEONTIEV, A N. Razvitiye pamyati: Eksperimental'noye issledovaniye vysshikh psikhologicheskikh funktsiy [Development of memory: Experimental research of higher psychological functions]. // A. N. LEONTIEV. Stanovleniye psikhologii deyatel'nosti: Ranniye raboty / Pod red. A.A. LEONTIEVA; D.A. LEONTIEV; E. E. SOKOLOVA. Moscow: Smysl, 2003. S. 27-206.

LEONTIEV, A. A.; LEONTIEV, D. A.; SOKOLOVA, E. E. Ranniye raboty A N Leont'yeva i ego put' k psikhologii deyatel'nosti [Early works of A N Leontiev and his path to the psychology of activity]. A N LEONTIEV. Stanovleniye psikhologii deyatel'nosti: Ranniye raboty. Trad. A.A. Leontieva; D. A. Leontiev; E. E. Sokolova. Moscow: Smysl, 2003, p. 3-24.

LOKHOV, M. I. et al. Dinamika formirovaniya proizvol'noy pamyati u detey [The dynamics of voluntary memory formation in children]. Psikhologicheskiy zhurnal, v. 14, n. 4, p. 56-65, 1993.

MESHCHERYAKOV, B. G. Kommentariy k stat'ye P. A. Myasoyeda « Onto- i kul'turogenez form zapominaniya: Replikatsiya eksperimentov A.N. Leont'yeva " [Commentary on the article of P. A. Myasoed "Ontological and cultural genesis of forms of memorizing: A replication of Leontiev's experiments”]. Voprosy psikhologii, n. 3, p. 117-118, 2013. 
MESHCHERYAKOV, B. G.; MOISEYENKO, E. V.; KONTORINA, V. K. Parallelogramm razvitiya pamyati: Ne mit, no trebuyet utochneniya [The parallelogram of memory development: not a myth, but requires improvement]. Psikhologicheskiy zhurnal Mezhdunarodnogo universiteta prirody obshchestva i cheloveka " Dubna ", n. 1, p. 19-41, 2008. [Elektronnyy resurs]. Available at: http:// www.psyanima.ru. Access: 10 Jan. 2019.

MYASOYED, P. A. "Parallelogramm »A N Leont'yeva, "geneticheskiy zakon » L S Vygotskogo i traditsiya nauchnoy shkoly [Leontiev's "parallelogram", L S Vygotsky's "genetic law" and traditions of a scientific school]. Voprosy psikhologii, n. 2, p. 105-117, 2003.

MYASOYED, P. A. Istoriya, logika i psikhologiya " parallelogramma Leont'yeva » [History, logic and the psychology of “"Leontiev’s parallelogram”]. Voprosy psikhologii, n. 6, p. 113-125, 2010.

MYASOYED, P. A. Onto- i kul'turogenez form zapominaniya: Replikatsiya eksperimentov A N Leont'yeva [Ontological and cultural genesis of forms of memorizing: a replication of Leontiev's experiments]. Voprosy psikhologii, n. 3, p. 106-117, 2013.

VIGOSTKI, L S Sobraniye sochineniy: v 6-ti t. T. 3. Problemy razvitiya psikhiki [Collected Works: In 6 T. T.]. Trad. A. M. Matyushkina. Moscow: Pedagogika, 1983. 368 p.

ZAPOROZHETS, A. V.; ELKONIN, D. B. Vklad rannikh issledovaniy A.N. Leont'yeva v razvitiye teorii deyatel'nosti [Contribution of A. N. Leontiev's early research in the development of the theory of activity]. Vestnik Moskovskogo Universiteta. Ser. 14. Psikhologiya, n. 4, p. 14-24, 1979.

ZAPOROZHETS, A. V.; ELKONIN, D. B. Problemy detskoy psikhologii v trudakh A N Leont'yeva and A N Leontiev i sovremennaya psikhologiya (Sbornik statey pamyati A N Leont'yeva) [Problems of child psychology in the works of A N Leontiev and A.N. Leontiev and modern psychology (Collection of articles by the memory of A N Leontiev)]. Trad. A. V. Zaporozhets; V. P. Zinchenko; O. V. Ovchinnikova. Moscow: Izd-vo Mosk, 1983, p. 66-78.

Recebido: 01 Jul 2019

Aceito: 30 Nov 2019

Comitê Editorial do Cedes/Coordenação deste número:

Silvia Cordeiro Nassif e Maria Silvia Pinto de Moura Librandi da Rocha 